\title{
Clean Hydrogen and Ammonia Synthesis in Paraguay from the Itaipu 14 GW Hydroelectric Plant
}

\author{
Massimo Rivarolo ${ }^{1, *}$, Gustavo Riveros-Godoy ${ }^{2}\left(\mathbb{D}\right.$, Loredana Magistri ${ }^{1}$ and Aristide F. Massardo ${ }^{1}$ \\ 1 Thermochemical Power Group, DIME, University of Genoa, Via Montallegro 1, 16145 Genoa, Italy; \\ loredana.magistri@unige.it (L.M.); massardo@unige.it (A.F.M.) \\ 2 Facultad de Ciencias y Tecnologia, Universidad Privada del Este (UPE), Area 5, Pdte Franco 7700, Paraguay; \\ gustavo.riveros@pti.org.py \\ * Correspondence: massimo.rivarolo@unige.it; Tel.: +39-010-335-2460
}

Received: 12 August 2019; Accepted: 28 October 2019; Published: 1 November 2019

\begin{abstract}
This paper aims at investigating clean hydrogen production from the large size (14 GW) hydroelectric power plant of Itaipu, located on the border between Paraguay and Brazil, the two countries that own and manage the plant. The hydrogen, produced by a water electrolysis process, is converted into ammonia through the well-known Haber-Bosch process. Hydraulic energy is employed to produce $\mathrm{H}_{2}$ and $\mathrm{N}_{2}$, respectively, from a large-scale electrolysis system and an air separation unit. An economic feasibility analysis is performed considering the low electrical energy price in this specific scenario and that Paraguay has strong excess of renewable electrical energy but presents a low penetration of electricity. The proposal is an alternative to increase the use of electricity in the country. Different plant sizes were investigated and, for each of them, ammonia production costs were determined and considered as a term of comparison with traditional ammonia synthesis plants, where $\mathrm{H}_{2}$ is produced from methane steam reforming and then purified. The study was performed employing a software developed by the authors' research group at the University of Genoa. Finally, an energetic, environmental, and economic comparison with the standard production method from methane is presented.
\end{abstract}

Keywords: hydrogen; electrolysis; storage; energy systems

\section{Introduction}

Nowadays, fossil fuels still provide more than $80 \%$ of the global energy demand [1]. However, since their intensive utilization in the last two centuries, the reserves of fossil fuels (coal, petroleum, and natural gas) are decreasing, especially when considering the continuous growth of world energy demand, in particular in developing countries. Furthermore, fossil fuels have a significant impact in terms of environmental pollution, both at local (emissions of $\mathrm{CO}, \mathrm{NOx}, \mathrm{SOx}$, and particulate matter) and global levels (due to their extensive $\mathrm{CO}_{2}$ emissions, with the consequent greenhouse effect). To face these energy and environmental problems, the promotion of sustainable solutions [2], including the synthesis of bio-fuels to replace traditional fossil fuels, represents an important step for the future [3-5].

Hydrogen has the potential to provide economically feasible, energy efficient, and environmentally sustainable solutions to the above reported issues related to fossil fuels. Hydrogen is a clean energy vector, characterized by zero emissions in terms of both $\mathrm{CO}_{2}$ and local pollutants. Furthermore, hydrogen can be produced throughout the water electrolysis process, employing renewable energy sources (RES) and water as the only input: in this way, the environmental impact in terms of pollutant emissions would be strongly reduced compared to $\mathrm{H}_{2}$ production from steam methane reforming, as reported in $[2,6]$. 
Hydrogen production by water electrolysis is a well-known process and several solutions, related to alkaline electrolyzer (AEC) technology, have already been available on the market for the last 50 years. Capital costs have decreased in the last ten years and they are expected to further reduce in the next future: as reported in recent literature [7], different solutions are available in terms of capacity (from $\mathrm{kW}$ to multi-MW for unit) and operating pressure (from 1 to 30 bar) with capital costs of about $1000-1200 € / \mathrm{kW}$ for large scale units.

Despite its advantages, hydrogen wide diffusion has yet to face some challenges related to its storage and distribution; in fact, even if hydrogen presents the highest energy content in mass terms, it has, on the other hand, a very low energy density $\left(0.09 \mathrm{~kg} / \mathrm{m}^{3}\right.$ at standard conditions) compared to traditionally employed fuels. Figure 1 shows the comparison in terms of gravimetric and volumetric density: it is evident that larger volumes are necessary for $\mathrm{H}_{2}$ storage, due to its low volumetric energy content, leading to higher costs.

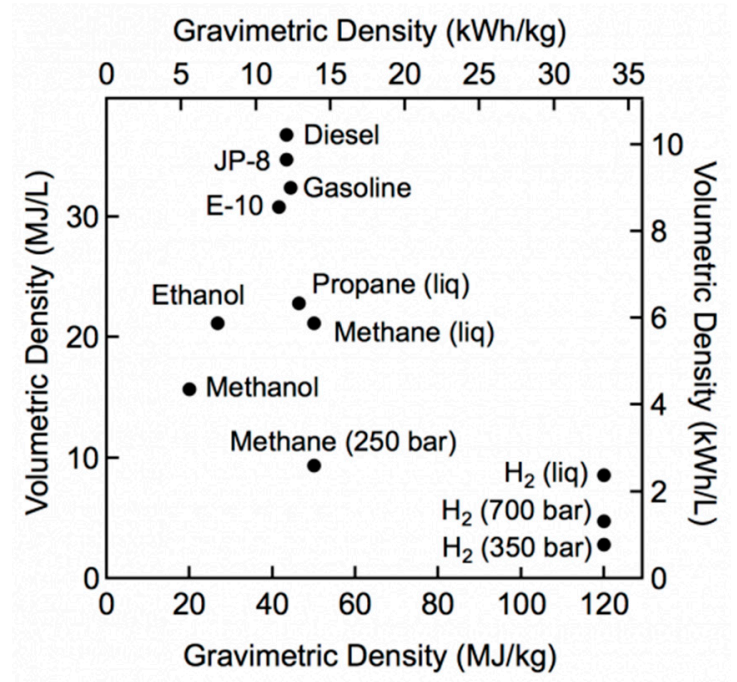

Figure 1. Gravimetric and volumetric density of hydrogen and other fuels [8].

For this reason, converting $\mathrm{H}_{2}$ into other fuels or "chemicals", with higher volumetric energy densities which are easier to store and transport, can be a viable solution, as reported in [9]. The potential advantages of converting renewable hydrogen, produced throughout the water electrolysis process, into methane $[6,10]$ or methanol [11] were investigated by the authors in previous research works. In this paper, the conversion of hydrogen into a liquid carrier, ammonia, is presented.

Ammonia $\left(\mathrm{NH}_{3}\right)$ has a wide range of applications, in particular in chemical industries, in absorption low-temperature cycles and in agriculture to produce fertilizers: this latest application is of particular interest in the Paraguay context. According to [12] the use of chemical fertilizers in Paraguay has shown an important growth from 2002 to 2014, the annual demand for nitrogenous fertilizers has increased from 34,934 up to 132,558 tons $(+379 \%)$. $\mathrm{NH}_{3}$ is a gas in standard conditions, but it is relatively easy to liquefy (at $\left.-33^{\circ} \mathrm{C}\right)$; therefore, it can be more efficiently stored compared to hydrogen: for this reason, ammonia can be also a convenient energy carrier for hydrogen $[13,14]$. Since $\mathrm{NH}_{3}$ is liquid at ambient pressure and higher temperatures compared to $\mathrm{H}_{2}$, liquefaction is less energy intensive. Storage and transportation of ammonia is a well-known industrial process: around 150 million of tons of $\mathrm{NH}_{3}$ per year are transported around the world, mainly by ships, rail, and pipelines [15]. Another key advantage of ammonia is that it does not contain carbon or sulphur, therefore it does not contribute to emissions in terms of $\mathrm{CO}_{2}, \mathrm{CO}$, and $\mathrm{SOx}$.

Table 1 shows a comparison between hydrogen storage with traditional methods (compressed and liquid hydrogen) and ammonia. Despite its lower power density, ammonia presents a higher energy density; moreover, its storage does not require large amounts of energy input that are required 
in case of hydrogen, which requires a large energy demand to bring it at high pressures (in case of compressed cylinders, $\mathrm{CH}_{2}$ ) or at cryogenic temperatures (in case of $\mathrm{LH}_{2}$ ).

Table 1. Comparison between hydrogen and ammonia.

\begin{tabular}{cccc}
\hline Unit & $\mathbf{C H}_{\mathbf{2}}$ & $\mathbf{L H}_{\mathbf{2}}$ & $\mathbf{N H}_{\mathbf{3}}$ \\
\hline Pressure [bar] & 700 & atmospheric & atmospheric \\
Temperature [ $\left.{ }^{\circ} \mathrm{C}\right]$ & - & -253 & -33 \\
Density $[\mathrm{g} / \mathrm{L}]$ & 35 & 71 & 674 \\
Power density $[\mathrm{kWh} / \mathrm{kg}]$ & 33.3 & 33.3 & 5.2 \\
Energy density [kWh/L] & 1.2 & 2.4 & 3.5 \\
Energy demand for storage & Medium & High & Low \\
\hline
\end{tabular}

Conventionally, $\mathrm{NH}_{3}$ is produced through the well-known Haber-Bosch process: nitrogen and hydrogen react at high pressure $(140-250 \mathrm{bar})$ and temperature $\left(300-500{ }^{\circ} \mathrm{C}\right)$, in presence of an iron catalyzer [16]. The reaction is exothermic, with the production of $92.4 \mathrm{~kJ} / \mathrm{mol}$.

$$
3 \mathrm{H}_{2}+\mathrm{N}_{2} \rightarrow 2 \mathrm{NH}_{3}
$$

According to Equation (1), $177 \mathrm{~kg}$ of $\mathrm{H}_{2}$ and $823 \mathrm{~kg}$ of $\mathrm{N}_{2}$ are theoretically necessary to produce 1 ton of ammonia.

Figure 2 shows the state-of-the-art method for ammonia synthesis in industrial process. $\mathrm{H}_{2}$ is conventionally produced from fossil fuels, through steam reforming of natural gas or coal. Steam reforming is currently the least expensive way to produce hydrogen, and it accounts for most of the commercially produced hydrogen. Due to its advantage from the economic standpoint, this method is widely employed in the industrial field to separate $\mathrm{H}_{2}$ atoms from carbon atoms in methane; on the other hand, the process results in fossil fuel consumption and in significant $\mathrm{CO}_{2}$ emissions. The gas produced by steam reforming has to be purified, separating $\mathrm{CO}$ and $\mathrm{CO}_{2}$, before entering the Haber-Bosch reactor for ammonia synthesis, with consequent costs [16,17]. The necessary amount of $\mathrm{N}_{2}$ is separated by air, through an air separation unit (ASU)—despite the process being well-known and the technology mature, a not-negligible amount of energy input is needed in terms of electricity, thermal energy, and fuel consumption. The simplified process is shown in Figure 2.

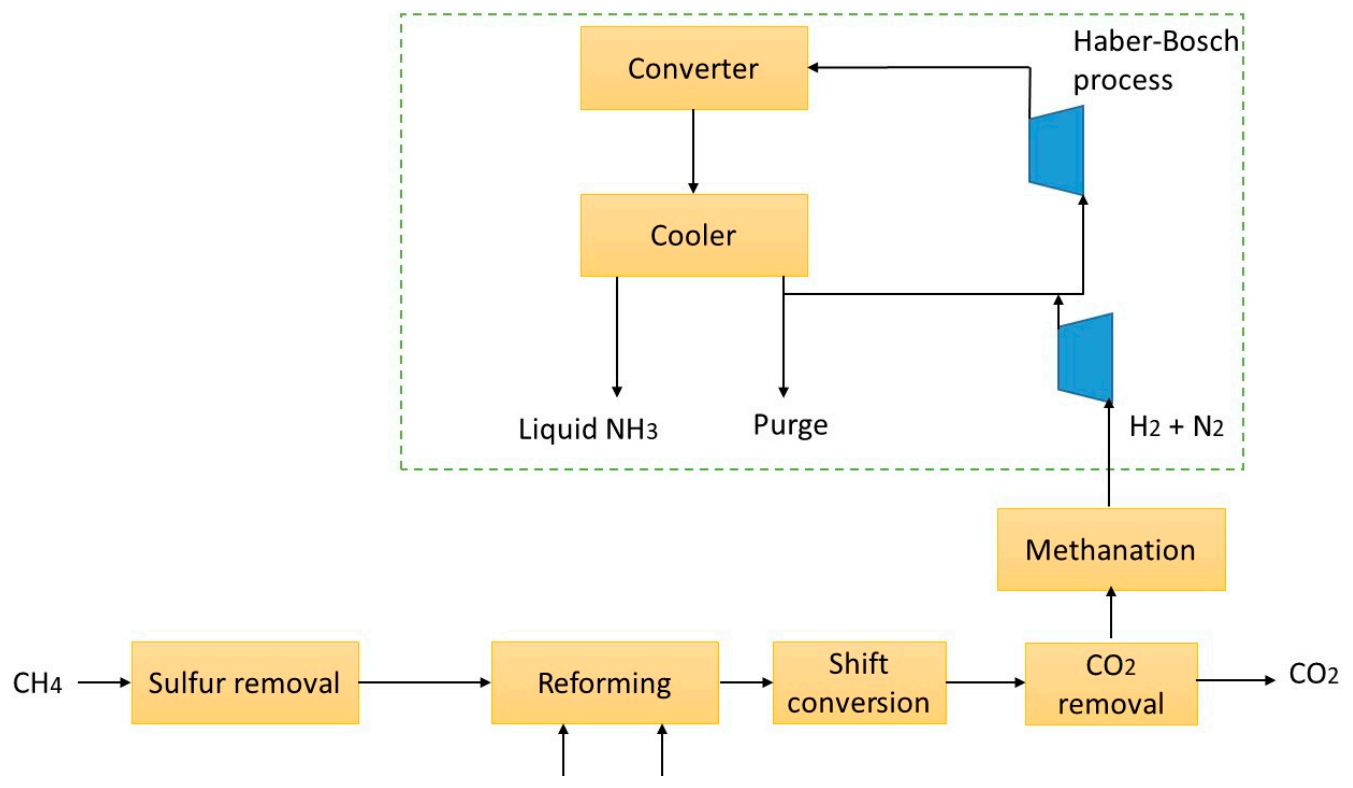

Figure 2. Industrial process for ammonia synthesis from natural gas [16]. 
In this paper, an alternative method for $\mathrm{NH}_{3}$ synthesis is investigated: hydrogen is produced by water electrolyzers, fed only by renewable energy produced from the Itaipu hydroelectric plant $(14 \mathrm{GW})$. The synthesis of ammonia by renewable sources has been studied in recent literature: Tuna et al. [18] performed a techno-economic study of several $\mathrm{NH}_{3}$ production systems based on renewable energy, including electrolysis and biomass gasification; more recently, Bicer et al [19] performed a life cycle assessment of various $\mathrm{NH}_{3}$ generation methods, defining the ecological effects of conventional ammonia generation paths. Producing ammonia from electrolyzers fed by renewable energy sources allows for a significant reduction of the environmental impact as no fossil fuels are consumed and the electrical energy needed in the process is produced by a renewable energy source. Another important advantage is the reduction of plant complexity as purification and gas treatment sections are not necessary anymore in this configuration (no SOx, $\mathrm{CO}$, or $\mathrm{CO}_{2}$ ): consequently, capital costs and fuel costs decrease.

On the other hand, capital costs related to electrolyzers and electrical energy costs must be taken into proper account. However, it is worth noting that in this particular scenario, electrical energy availability is very large as the hydroelectric plant of Itaipu (14 GW, owned by Brazil and Paraguay) represents the largest renewable facility in the world in terms of energy production. In 2016, the plant obtained the production record of $103.1 \mathrm{TWh}$, and, in 2017 and 2018, the production exceeded the considerable amount of 96 TWh [20]. In 2018, Itaipu covered 15\% of total electrical energy demand of Brazil (9.2 GW in terms of average produced power) and 90\% of Paraguay (1.7 GW in terms of average produced power) [20]. It is important to underline that Paraguay owns $50 \%$ of the installed capacity in Itaipu (7 GW) but currently uses less than $2 \mathrm{GW}$. Moreover, Paraguay has another two large size hydroelectric plants, Acaray (220 MW) and Yasyreta (3200 MW), the last one is owned jointly with Argentina.

In periods characterized by large hydraulic availability, water is spilled from the reservoir, without getting to the turbines (20 turbines, $700 \mathrm{MW}$ each) for energy production: in 2017 and 2018, the average spilled power was $214 \mathrm{MW}$ and $81 \mathrm{MW}$, respectively [20]. This energy, which has a strong time-dependent nature in the different periods of the year, can also be employed for $\mathrm{H}_{2}$ production by water electrolysis. In the other periods of the year, to ensure a constant $\mathrm{H}_{2}$ production, energy could be purchased from the national grid, as investigated by authors in previous works $[6,10,11]$.

The innovative aspect of the present study, compared to the ones reported in recent literature $[18,19]$, is the analysis of a large size plant for ammonia synthesis employing renewable electrical energy only, evaluating the solution not only from the environmental standpoint, but also considering the economic aspects, comparing the average synthesis costs to the standard method.

\section{Materials and Methods}

In this study, the use of electrical energy from Itaipu for $\mathrm{NH}_{3}$ production was investigated. Hydrogen is produced by large size electrolyzers [21,22] (30 bar, modules of $2 \mathrm{MW}$, efficiency $75 \%$ corresponding to electrical demand of $4.7 \mathrm{kWh} / \mathrm{Nm}^{3} \mathrm{H}_{2}$ ), while $\mathrm{N}_{2}$ is obtained by an ASU [17] (electrical demand of $160 \mathrm{kWh} /$ ton $\mathrm{O}_{2}$ ); then, the reactants are compressed and sent to the Haber-Bosch section for ammonia synthesis. Electrical energy for the process is produced by the Itaipu dam. Figure 3 shows a simplified scheme of the plant. Considering that, as reported in the National Energy Balance [23], $73 \%$ of the produced electricity is exported (43.6 TWh in 2017), the increase of the internal electrical energy consumption of Paraguay, due to the installation of a large scale power-to-ammonia plant, does not represent a problem for the electric balance of the country. Figure 3 shows a simplified scheme of the plant: it is evident that Paraguay employs only a part of its $50 \%$ share, since energy demand is lower than the generated power. Comparing the process with the traditional one, previously shown in Figure 2, it is worth noting that the proposed plant lay-out does not require the sections related to fuel purification (sulphur removal), steam reforming (which include the injection of steam at high temperature) and the $\mathrm{CO}_{2}$ separation from the syngas; thus, the complexity of the plant is significantly reduced. 


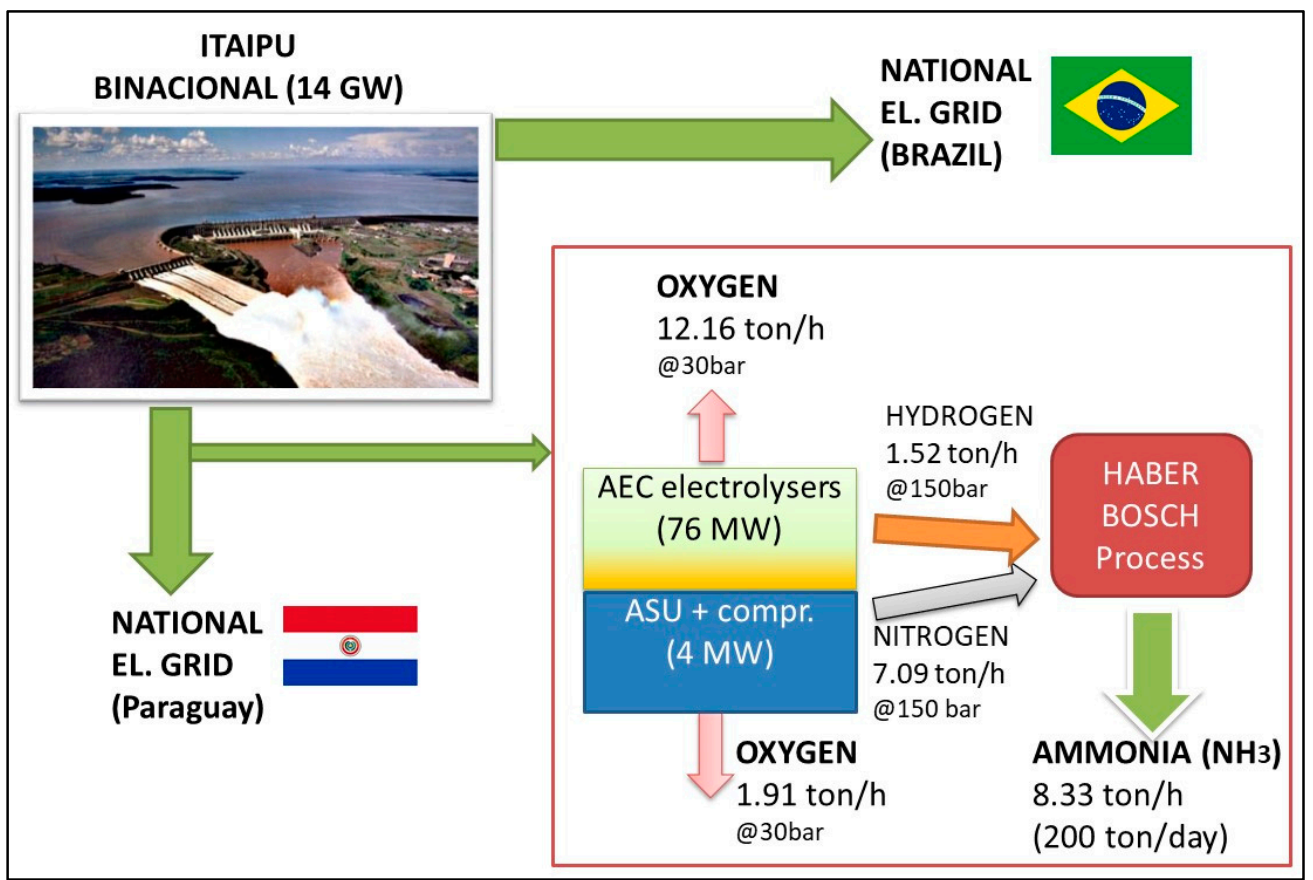

Figure 3. Simplified scheme for ammonia synthesis from Itaipu electrical energy.

Assuming a system with a production size of 200 ton/day of $\mathrm{NH}_{3}$, which is a typical commercial scale $[16,17]$, the analysis is performed in two steps: (i) mass and energy flows are calculated to define the size of the main plant components; (ii) the economic analysis is performed, calculating ammonia production costs and performing a comparison with ammonia market values.

The main assumptions considered for the mass and energy flows calculation are reported in Table 2, based on standard values from literature and/or from the industrial market $[16,17,21,22]$.

Table 2. Main technical assumptions for energy analysis $[16,17,21,22]$.

\begin{tabular}{cc}
\hline 2 MW Electrolyzers & \\
Electrical demand & $4.7 \mathrm{kWh} / \mathrm{Nm}^{3}$ di $\mathrm{H}_{2}$ \\
Pressure & $30 \mathrm{bar}$ \\
Efficiency & $75 \%$ \\
$\mathrm{O}_{2}: \mathrm{H}_{2}$ mass ratio & $8: 1$ \\
Air Separation Unit & \\
Electrical demand & $160 \mathrm{kWh} /$ ton $\mathrm{O}_{2}$ \\
Haber-Bosch section & \\
$\mathrm{H}_{2}$ compressor efficiency & $70 \%$ \\
$\mathrm{~N}_{2}$ compressor efficiency & $85 \%$ \\
Working Pressure & $150 \mathrm{bar}$ \\
Conversion efficiency & $96 \%$ \\
$\mathrm{H}_{2}: \mathrm{N}_{2}$ mass ratio & $6: 28$ \\
\hline
\end{tabular}

The resulting mass and energy flows are reported in Figure 3. Considering a nominal production of 200 ton/day of $\mathrm{NH}_{3}$ (equivalent to $8330 \mathrm{~kg} / \mathrm{h}$ ), about $1520 \mathrm{~kg} / \mathrm{h}$ of $\mathrm{H}_{2}$ and $7100 \mathrm{~kg} / \mathrm{h}$ of $\mathrm{N}_{2}$ are needed as reactants. $\mathrm{H}_{2}$ is produced by the electrolyzers at 30 bar: with the assumed efficiency, a 2 MW unit is able to produce $38 \mathrm{~kg} / \mathrm{h}$; thus, 40 units for a total of $80 \mathrm{MW}$ are needed. As the mass ratio between $\mathrm{O}_{2}$ and $\mathrm{H}_{2}$ in the electrolysis process is $8: 1$, about $12,160 \mathrm{~kg} / \mathrm{h}$ of oxygen are co-produced. As far as the $\mathrm{N}_{2}$ is concerned, considering air composition in mass terms $\left(75.6 \% \mathrm{~N}_{2}, 23.1 \% \mathrm{O}_{2}\right)$, about $2160 \mathrm{~kg} / \mathrm{h} \mathrm{of} \mathrm{O}_{2}$ are co-produced; considering the assumed consumptions for ASU and compressors, an additional $4 \mathrm{MW}$ are required as input. 


\section{W-ECoMP Software}

As far as the economic analysis is concerned, it is performed throughout W-ECoMP software, developed by the Thermochemical Power Group (TPG) at the University of Genoa [24] and recently employed in several research funded projects $[6,11,25,26]$. W-ECoMP has a modular structure (more than 50 modules are implemented now), which can be easily combined by the user in order to simulate different kinds of plants (i.e., power to fuel plants, smart grids, combined cycles). One of the most important features of $\mathrm{W}$-ECoMP is the possibility of performing a thermo-economic analysis at two different hierarchical levels to optimize the operating strategy for existing energy systems (low level) and also the size of one or more components during the plant design (high level). Capital and variable costs are considered for the high level optimization, while only variable costs are considered to optimize the operating strategy. In the design optimization, the size of each component is evaluated together with its capital cost. The evaluation of the optimal operating strategy is carried out at the lower level of optimization according to the actual energy load demands (i.e., electricity, heating, and cooling energy). W-ECoMP receives as input: (i) energy load curves versus time; (ii) fuel and/or electricity costs and the economic scenario where the plant operates; (iii) component capital costs vs. size; and (iv) O\&M costs vs. time. The software aims at minimizing a cost function (objective function) that is representative of plant annual costs, comprehensive of variable and fixed costs. Fixed costs are evaluated thanks to cost functions, obtained by literature review and/or real market data provided by TPG industrial partners and implemented in the software libraries for each module. The sum of capital costs of the single modules furnishes the purchased equipment cost (PEC). From the PEC, the Total Capital Investment (TCI) can be estimated by considering all the accessory costs (engineering costs, installation costs, land, piping, etc.). The weight of these voices is calculated as a percentage of PEC [11,27] and it depends on the scenario where the plant is operating and on the plant technology. Table 3 shows the main values, assumed in this specific case, based on previous research works [11] and data related to the Paraguayan context: the total TCI/PEC ratio is assumed equal to 1.75. It is worth noting that the values are affected not only by the plant typology, but also by the scenario where the plant is installed.

Table 3. Main voices for economic analysis in W-ECoMP software.

\begin{tabular}{cc}
\hline Voice of Cost & \% of PEC \\
\hline Installation & $10 \%$ \\
Piping & $5 \%$ \\
Instrumentation and control & $3 \%$ \\
Electrical equipment & $3 \%$ \\
Land & $1 \%$ \\
Civil works & $10 \%$ \\
Service facilities & $5 \%$ \\
Direct costs & $\mathbf{3 7 \%}$ \\
Construction & $8 \%$ \\
Engineering & $15 \%$ \\
Contingencies & $5 \%$ \\
Startup & $\mathbf{6 5 \%}$ \\
Fixed Capital Investment (FCI) & $3 \%$ \\
Working capital & $7 \%$ \\
Total & $\mathbf{7 5 \%}$ \\
TCI/PEC & $\mathbf{1 7 5} \%$ \\
\hline
\end{tabular}

As far as variable costs are concerned, they include mainly fuel and energy consumptions: in this case, since the considered plant is a power-to-ammonia plant, the main voice is represented by electrical energy cost. Electrical energy cost is based on spilled energy availability in the different periods of the year, according to energy demands from the electrical grid and water availability at the reservoir. Electrical energy costs are assumed to be $7 € / \mathrm{MWh}$ for spilled energy and $30 € / \mathrm{MWh}$ for electrical energy purchased from the grid, when spilled energy is not available or not sufficient to feed the 
power-to-ammonia plant. More details about the W-ECoMP software have been reported in previous publications by the authors $[11,25]$.

\section{Results}

In the framework of the present study, different power-to-ammonia system's sizes were analyzed and compared from the economic standpoint: for each size, $\mathrm{NH}_{3}$ synthesis costs are evaluated and compared with the state-of-the-art process.

As the first step, a fixed size of the system, reported in Figure 3, is considered: purchased equipment costs are calculated considering cost functions implemented in the W-ECoMP software, for the different plant sections, as reported below (compressors costs are included in the Haber-Bosch section):

$$
\begin{gathered}
C_{\text {electrolysers }}=1300000 \cdot P_{\mathrm{mod}}^{0.9} \cdot N_{\mathrm{mod}}^{0.9} \\
C_{\text {ASU }}=204270 \cdot \mathrm{M}_{\text {Oxygen }}^{0.65} \\
C_{\text {Haber-Bosch }}=109000 \cdot M_{\text {in }}^{0.65}
\end{gathered}
$$

From the above reported cost functions, the purchased equipment cost (PEC) of the plant is calculated. Adding the accessory costs (reported in Table 2), it is possible to evaluate the total capital investment (TCI) and, therefore, the annual fixed costs. Variable annual costs are mainly related to electrical energy consumption. Figure 4 reports the main results in terms of annual costs and their distribution, considering a fixed plant size for the production of 200 ton/day of $\mathrm{NH}_{3}$ and a capacity factor of $8400 \mathrm{~h}$ per year, comparable with the ones available on the market for $\mathrm{NH}_{3}$ synthesis.

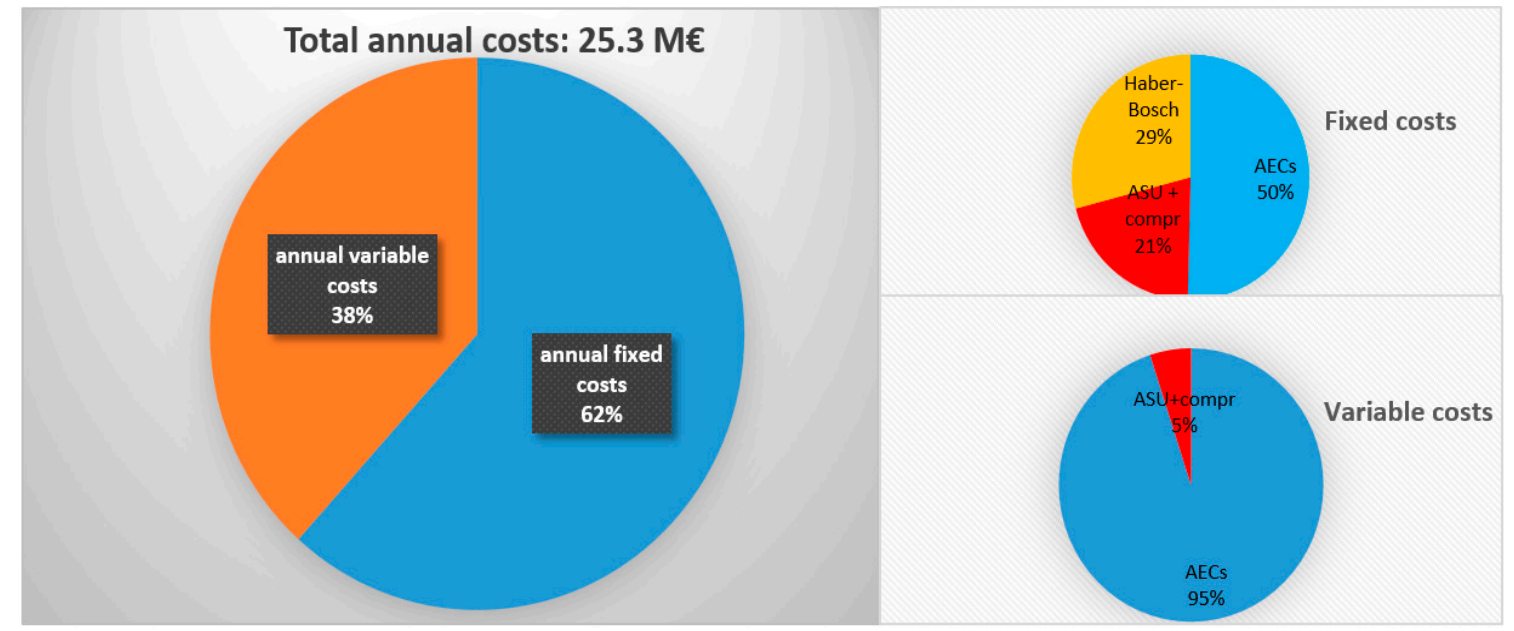

Figure 4. Total annual costs distribution (left) and detail of fixed and variable costs (right) for a 200 ton/day $\mathrm{NH}_{3}$ plant.

Considering the above reported capacity factor of the plant, it is easy to calculate, knowing the annual amount of produced ammonia (70,000 ton/year), the production specific cost, which is $366 € /$ ton. This cost is lower than the market price of 350-550 \$/ton [28] for ammonia synthesis from methane steam reforming (depending on the market price of $\mathrm{CH}_{4}$, which is affected by several parameters). Therefore, the proposed method is economically attractive, at least in the proposed scenario. It is worth noting that the above reported production cost can be further reduced by considering the sale of the high amounts of oxygen co-produced in the electrolysis process and in the ASU, after proper storage and distribution. The $\mathrm{O}_{2}$-selling option is not included in this analysis; however, it would improve economic performance, even if a storage and transportation system would be necessary.

From the environmental point of view, the proposed system presents significant advantages, as it employs only renewable energy, while the traditional system presents high fuel consumption and $\mathrm{CO}_{2}$ 
emissions. Considering the same plant size in terms of ammonia production (200 ton/day, corresponding to 70,000 ton/year), about 25,000 ton/year of natural gas would be necessary, with a consequent emission of 68,000 ton/year of carbon dioxide. Therefore, the proposed solution also presents a significant advantage in terms of fossil fuels savings and the avoidance of emissions of greenhouse gases $\left(\mathrm{CO}_{2}\right)$.

\section{Sensitivity Analysis: Effect of Plant Size}

The results reported in the previous section refer to a "standard" size of the plant, able to produce 200 ton/day of ammonia, for a total annual production of 70,000 tons. However, the reported value is a standard for a low-medium capacity plant for ammonia synthesis. In this subsection, the economic impact of the plant size is investigated.

Table 4 reports the influence of the plant size in terms of $\mathrm{NH}_{3}$ production costs: the aim of the analysis was to determine the optimal size that allows for annual production costs minimization. Even in this case, the analysis does not take into account the option of oxygen storage, distribution, and selling: the high amount of coproduced $\mathrm{O}_{2}$ is vent into the atmosphere.

Table 4. Ammonia synthesis costs for different sizes.

\begin{tabular}{cccccc}
\hline Installed Power [MW] & $\mathbf{8 0}$ & $\mathbf{2 0 0}$ & $\mathbf{3 0 0}$ & $\mathbf{4 0 0}$ & $\mathbf{6 0 0}$ \\
\hline $\mathrm{H} 2$ (electrolyzers) [kg/h] & 1520 & 3800 & 5700 & 7600 & 11,400 \\
$\mathrm{O}_{2}$ (electrolyzers) [kg/h] & 12,160 & 30,400 & 45,600 & 60,600 & 91,200 \\
$\mathrm{~N}_{2}$ (ASU) [kg/h] & 7093 & 17,733 & 26,600 & 35,466 & 53,200 \\
$\mathrm{O}_{2}$ (ASU) [kg/h] & 1912 & 4780 & 7170 & 9434 & 14,340 \\
Total energy demand [GWh] & 705.7 & 1717.5 & 2560.7 & 3280.3 & 5121.4 \\
Spilled energy amount & $70 \%$ & $65 \%$ & $55 \%$ & $40 \%$ & $25 \%$ \\
\hline Capital costs & & & & & \\
\hline Electrolyzers [M€] & 68.1 & 155.4 & 223.9 & 290.0 & 417.7 \\
ASU [M€] & 27.7 & 50.3 & 65.5 & 78.9 & 102.8 \\
Haber-Bosch [M€] & 39.4 & 71.4 & 93.0 & 112.1 & 145.9 \\
Total PEC [M€] & 135.2 & 277.2 & 382.3 & 481.6 & 666.4 \\
TCI [M€] & 236.6 & 485.0 & 669.0 & 841.3 & 1166.1 \\
\hline Specific capital cost [M€/MW] & $\mathbf{2 9 5 7}$ & $\mathbf{2 4 2 5}$ & $\mathbf{2 2 3 0}$ & $\mathbf{2 1 0 3}$ & $\mathbf{1 9 4 3}$ \\
\hline Annual fixed costs [M€/year] & 15.7 & 32.3 & 44.6 & 56.1 & 77.7 \\
Annual variable costs [M€/year] & 9.8 & 25.8 & 44.4 & 66.9 & 123.4 \\
Avoided CO 2 [10 ${ }^{3}$ ton/year] & 68 & 170 & 255 & 340 & 510 \\
NH $_{3}$ prod [ton/day] & 200 & 500 & 750 & 1000 & 1500 \\
NH $_{3}$ prod cost [€/ton] & $\mathbf{3 6 6}$ & $\mathbf{3 3 2}$ & $\mathbf{3 4 3}$ & $\mathbf{3 5 1}$ & $\mathbf{3 8 3}$ \\
\hline
\end{tabular}

It is worth observing that by increasing the power-to-ammonia size, two different phenomena take place:

- Despite the increase of the overall plant TCI, the specific investment cost becomes lower from the effect of size, from $2875 € / \mathrm{kW}$ for a low-medium capacity plant (200 ton/day of $\mathrm{NH}_{3}$ ) up to $1888 € / \mathrm{kW}$ for a large capacity one (1500 ton/day of $\left.\mathrm{NH}_{3}\right)$;

- On the other hand, the amount of low-cost spilled energy available for the ammonia plant gets progressively lower for higher sizes: as consequence, while for lower capacity plants the fixed costs are more significant than variable costs (electrical energy), for higher sizes the situation is the opposite, as electricity has an higher cost ( $30 € / \mathrm{MWh})$.

The combination of these two effects is that the optimal value, from the economic point of view, is an intermediate size of about $200 \mathrm{MW}$ : the highest production costs occur at lower sizes ( $366 € /$ ton at $80 \mathrm{MW}$, due to higher capital costs) and at large sizes ( $383 € /$ ton at $600 \mathrm{MW}$, due to higher electricity costs). However, it is worth noting that specific synthesis costs for large size $\mathrm{NH}_{3}$ synthesis from the traditional method $\left(\mathrm{CH}_{4}\right.$ steam reforming) reported by IEA are in the range 350-550 \$/ton [28], 
meaning that the presented synthesis method is economically feasible. As far as economic analysis is concerned, the results are interesting, thanks to the large availability of low cost electrical energy from the Itaipu plant.

Figure 5 shows the main results, focusing on the trend of annual costs and ammonia specific production cost as function of the plant installed power. It is worth noting how the impact of variable costs becomes more and more significant as the size increases: at the highest size (600 MW), the contribute is about two times higher than fixed annual costs; at intermediate size ( $300 \mathrm{MW}$ ) the two contributes are equal, while at the lowest size $(80 \mathrm{MW})$, fixed costs are significantly higher.

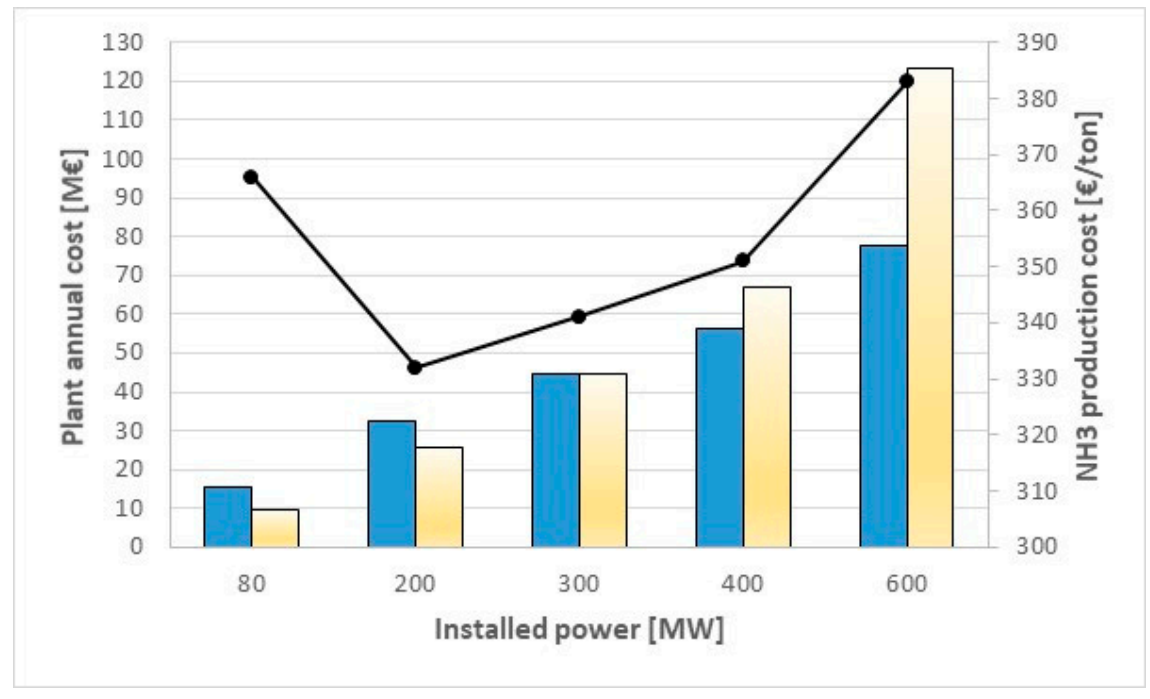

Figure 5. Ammonia specific cost and annual costs (variable and fixed) vs. plant size.

\section{Discussion and Conclusions}

In this study, a solution for ammonia synthesis from renewable energy has been investigated from the technical and economic points of view, considering as a case study the Itaipu 14 GW hydro power plant, which is the largest hydroelectric facility in the world in terms of energy production, where considerable amounts of low-cost (spilled) energy are available. The hydraulic energy has been employed to produce hydrogen by a large-scale system of commercial pressurized (30 bar) alkaline electrolyzers; then, the hydrogen is mixed with the nitrogen, separated by air with a commercial unit, and the two gases are sent to a chemical reactor for ammonia synthesis. A time-dependent economic analysis has been performed using a software tool developed by the authors, calculating annual plant costs and ammonia synthesis costs. The proposal presents an interesting strategy for greater use of clean electrical energy toward a low carbon economy in Paraguay.

A first energy and economic analysis was performed considering a plant size of 200 ton/day of $\mathrm{NH}_{3}$, then the influence of the plant size was investigated, considering different large size systems in order to optimize the ammonia production cost. The results allowed the following conclusions to be drawn:

- For all the investigated sizes, ammonia production costs are lower than $400 € /$ ton, (market prices are 350-550 \$/ton), showing a good economic feasibility.

- For the lowest investigated size (200 ton/day of ammonia, $80 \mathrm{MW}$ of electrolyzers), the plant specific cost is higher (about $2900 €$ /installed MW) due to the higher specific capital cost of the components.

- For the highest investigated size (1500 ton/day of ammonia, $600 \mathrm{MW}$ of electrolyzers), capital costs are considerably lower $(1900 € /$ installed MW); on the other hand, since the amount of electrical energy that has to be purchased by the grid is higher, variable costs increase and the production cost increases as well. 
- The best solution is represented by an intermediate size of about $200 \mathrm{MW}$ of installed AECs, as shown in Figure 5, corresponding to a production cost of about $340 € /$ ton.

- From the environmental standpoint, the so produced $\mathrm{NH}_{3}$ is $100 \%$ green, as it is produced by renewable electricity only; moreover, the emissions of $\mathrm{CO}_{2}$ are avoided, as reported in the previous section.

- The economic results can be improved by considering the storage, distribution and sale of the very large amounts of pure oxygen produced during the electrolysis process; however, this study would require further analysis related to the $\mathrm{O}_{2}$ market in Paraguay and Brazil in order to evaluate the related transportation costs. This analysis, partially performed by the authors' research group in a previous study [29], may be integrated in a future work.

In conclusion, the proposed method for ammonia synthesis presents several advantages compared to the state-of-the-art, in particular in environmental terms. Furthermore, considerable amounts of pure oxygen are produced and this could be a significant benefit from the economic standpoint. However, it must be noted that the positive economic results are related to the availability of a very large amount of electrical energy at relative low cost, which depends on the scenario where the plant operates: in countries characterized by large share of renewable electrical energy production, the proposed layout can be a worthy solution.

Finally, it is worth remarking that the proposed approach has a general validity, therefore it can be applied to different plant sizes and different economic scenarios, evaluating the influence of economic parameters (i.e., electrical energy price) on the results.

Author Contributions: Conceptualization, M.R. and A.F.M.; methodology, M.R. and G.R.-G.; software, M.R. and A.F.M.; validation, M.R.; formal analysis, M.R. and G.R.-G.; investigation, M.R. and L.M.; data curation, M.R.; writing-original draft preparation, M.R.; writing—review and editing, A.F.M.; supervision, L.M. and A.F.M.

Funding: This research received no external funding.

Conflicts of Interest: The authors declare no conflict of interest.

\section{References}

1. El Amam, R.S.; Ozcan, H. Hydrogen energy, economy and storage: Review and recommendation. Int. J. Hydrogen Energy 2019, 44, 15072-15086. [CrossRef]

2. Acar, C.; Dincer, I. Review and evaluation of hydrogen production options for better environment. J. Clean. Prod. 2019, 218, 835-849. [CrossRef]

3. Ferrari, M.L.; Traverso, A.; Massardo, A.F. Smart polygeneration grids: Experimental performance curves of different prime movers. Appl. Energy 2016, 162, 622-630. [CrossRef]

4. Ferrari, M.L.; Rivarolo, M.; Massardo, A.F. Hydrogen production system from photovoltaic panels: Experimental characterization and size optimization. Energy Convers. Manag. 2016, 116, 194-202. [CrossRef]

5. Zaccaria, V.; Tucker, D.; Traverso, A. Operating strategies to minimize degradation in fuel cell gas turbine hybrids. Appl. Energy 2017, 192, 437-445. [CrossRef]

6. Rivarolo, M.; Magistri, L.; Massardo, A.F. Hydrogen and methane generation from large hydraulic plant: Thermo-economic multi-level time-dependent optimization. Appl. Energy 2014, 113, 1737-1745. [CrossRef]

7. Schmidt, O.; Gambhir, A.; Staffell, I.; Hawkes, A.; Nelson, J.; Few, S. Future cost and performance of water electrolysis: An expert elicitation study. Int. J. Hydrogen Energy 2017, 42, 30470-30492. [CrossRef]

8. US Department of Energy (DOE). Available online: https://www.energy.gov/eere/fuelcells/hydrogen-storage (accessed on 10 September 2019).

9. Gotz, M.; Letfebvre, J.; Mörs, F.; Koch, A.M.; Graf, F.; Bajohr, S.; Reimert, R.; Kolb, T. Renewable Power-to-Gas: A technological and economic review. Renew. Energy 2016, 85, 1371-1390. [CrossRef]

10. Rivarolo, M.; Massardo, A.F. Optimization of large scale bio-methane generation integrating "spilled" hydraulic energy and pressurized oxygen blown biomass gasification. Int. J. Hydrogen Energy 2013, 38, 4986-4996. [CrossRef] 
11. Rivarolo, M.; Bellotti, D.; Mendieta, A.; Massardo, A.F. Hydro-methane and methanol combined production from hydroelectricity and biomass: Thermo-economic analysis in Paraguay. Energy Convers. Manag. 2014, 79, 74-84. [CrossRef]

12. Ortiz, A.; Venialgo, M.; Ferreira, N. El uso de Fertilizantes Químicos y el Crecimiento de la Agricultura Paraguaya. Contab. Mark. Empresa 2017, 3. Available online: www.unae.edu.py/ojs/index.php//facem/article/ view/81 (accessed on 10 September 2019).

13. Lan, R.; Irvine, J.T.S.; Tao, S. Ammonia and related chemicals as potential indirect hydrogen storage materials. Int. J. Hydrogen Energy 2012, 37, 1482-1494. [CrossRef]

14. Klerke, A.; Christensen, C.H.; Nørskov, J.K.; Vegge, T. Ammonia for hydrogen storage: Challenges and opportunities. J. Mater. Chem. 2008, 18, 2304-2310. [CrossRef]

15. Lamb, K.E.; Dolan, M.D.; Kennedy, D.F. Kennedy Ammonia for hydrogen storage; A review of catalytic ammonia decomposition and hydrogen separation and purification. Int. J. Hydrogen Energy 2019, 44, 3580-3593. [CrossRef]

16. Bartels, J.R. A Feasibility Study of Implementing an Ammonia Economy; Iowa State University: Ames, IA, USA, 2008.

17. Banaszkiewicz, T.; Chorowski, M.; Gizicki, W. Comparative analysis of oxygen production for oxy-combustion application. Energy Procedia 2014, 51, 127-134. [CrossRef]

18. Tunå, P.; Hulteberg, C.; Ahlgren, S. Techno-Economic assessment of nonfossil ammonia production. Environ. Prog. Sustain. Energy 2014, 33, 1290-1297. [CrossRef]

19. Bicer, Y.; Dincer, I.; Vezina, G.; Raso, F. Impact Assessment and Environmental Evaluation of Various Ammonia Production Processes. Environ. Manag. 2017, 59, 842-855. [CrossRef] [PubMed]

20. Available online: www.itaipu.gov.br (accessed on 30 May 2019).

21. Sorce, A.; Bellotti, D.; Rivarolo, M.; Magistri, L. Techno-economic analysis for the integration of a power to fuel system with a CCS coal power plant. J. $\mathrm{CO}_{2}$ Util. 2019, 33, 262-272. [CrossRef]

22. Available online: www.hydrogenics.com/wp-content/uploads/HyLYZER_600_3MW.pdf (accessed on 10 September 2019).

23. VMME (Vice-Ministerio de Minas y Energía). Balance Energético Nacional del Paraguay; VMME: San Lorenzo, Paraguay, 2018.

24. Available online: http://www.tpg.unige.it/TPG/software/ (accessed on 30 May 2019).

25. Rivarolo, M.; Cuneo, A.; Traverso, A.; Massardo, A.F. Design optimization of smart poly-generation energy districts through a model based approach. Appl. Therm. Eng. 2016, 99, 291-301. [CrossRef]

26. Rivarolo, M.; Rattazzi, D.; Magistri, L. Best operative strategy for energy management of a cruise ship employing different distributed generation technologies. Int. J. Hydrogen Energy 2018, 43, 23500-23510. [CrossRef]

27. Bejan, A.; Tsatsaronis, G.; Moran, M. Thermal Design and Optimization; Wiley: Hoboken, NJ, USA, 1995.

28. Philibert, C. Producing Ammonia and Fertilizers: New Opportunities from Renewables; International Energy Agency (IEA): Paris, France, 2017.

29. Rivarolo, M.; Marmi, S.; Riveros-Godoy, G.; Magistri, L. Development and assessment of a distribution network of hydro-methane, methanol, oxygen and carbon dioxide in Paraguay. Energy Convers. Manag. 2014, 77, 680-689. [CrossRef]

(C) 2019 by the authors. Licensee MDPI, Basel, Switzerland. This article is an open access article distributed under the terms and conditions of the Creative Commons Attribution (CC BY) license (http://creativecommons.org/licenses/by/4.0/). 